\title{
AVAliaÇÃo de PROGRAMaS de ALIMENTAÇÃo PARA PINTOS DE CORTE SUBMETIDOS A JEJUM DE 72 HORAS PÓS-ECLOSÃO
}

\author{
Evaluation of programs of feeding for broiler chicks submitted the fast three days \\ after-heatching during pre-starter and starter phases \\ José Humberto Vilar da Silva ${ }^{1}$, Marcelo Luís Gomes Ribeiro ${ }^{4}$, \\ José Jordão Filho², Edson Lindolfo da Silva ${ }^{3}$
}

\begin{abstract}
RESUMO
Com o experimento, avaliou-se uma condição prática de $72 \mathrm{~h}$ de jejum e o efeito de três programas de alimentação sobre o desempenho de 576 pintos da linhagem Cobb-Avian Farms aos sete e vinte um dias de idade. Os programas de alimentação foram: $P_{1}$ $=$ ração inicial; $\mathrm{P}_{2}$ e $\mathrm{P}_{3}=$ rações pré-iniciais. Os $\mathrm{P}_{1}$ e $\mathrm{P}_{2}$ foram aqueles constantes nas Tabelas Brasileiras (2000 e 2005), enquanto o $\mathrm{P}_{3}$ foi um programa utilizado nas integrações avícolas. O delineamento experimental utilizado foi o inteiramente ao acaso, com três tratamentos, cada um com 12 repetições e dezesseis aves por unidade experimental. Aos 7 dias, os programas com dietas pré-iniciais proporcionaram melhor conversão alimentar $(\mathrm{P} \leq 0,05)$ e médias de peso vivo de 12,46 e $15,17 \mathrm{~g}$, respectivamente, superiores ao programa com ração inicial. De 1 a 21 dias, os programas de alimentação utilizando dietas pré-iniciais proporcionaram maior consumo de ração, peso vivo e ganho de peso $(\mathrm{P} \leq 0,05)$. Os resultados mostraram que os programas de alimentação com dietas pré-iniciais melhoram o desempenho de pintos de corte até 21 dias de idade submetidos a longos períodos de restrição alimentar pós-eclosão.
\end{abstract}

Termos para indexação: Consumo de ração, desempenho inicial, restrição alimentar.

\section{ABSTRACT}

The experiment was conducted in order to evaluate in practical condition the three feeding programme for broiler during 72 $\mathrm{h}$ of fast after heatching on pre-starter and starter phases. A total of 576 chickens Cobb-Avian Farms from seven to twenty days old were utilized. The feeding programs were: P1 = initial ration; P2 and P3 = pre-starter rations. P1 and P2 were similar to described in the Brazilian Tables (2000 and 2005), while P3 was the same program used in the poultry integrations. The experimente was in the a completely randomized design, with three treatments, each one with 12 portions and sixteen chickens per experimental unit. Accord to results at 7 days, the programs with pre-starter diets provided better $(\mathrm{P}<0.05)$ feed conversion and averages of live weight of 12.46 and $15.17 \mathrm{~g}$, respectively, superiors to the program with initial ration. From 1 to 21 days, the feeding programs using pre-starter diets provided higher feed intake, live weight and weight gain. The results showed that the feeding programs with pre-starter diets improve the performance of broiler chicken up to 21 days old submitted to long periods of feeding programme by using the feed restriction after-heatching.

Index terms: Feed intake, performance, feed restriction.

(Recebido para publicação em 21 de dezembro de 2005 e aprovado em 7 de junho de 2006)

\section{INTRODUÇÃO}

Em condições práticas, a espera para se obter a eclosão máxima (GEYRA et al., 2001b), secagem da penugem (BIGOT et al., 2003), seleção, sexagem, vacinação e transporte, atrasa o acesso dos pintinhos ao alimento exógeno de um a dois dias.

No final da incubação, nota-se um súbito aumento na expressão dos RNAm, que codificam para a sacarase, isomaltase e o transportador de glicose sódio dependente na célula apical da borda em escova do jejuno do embrião (GEYRA et al., 2002; SKLAN et al., 2003). Logo após a eclosão, as habilidades de digerir e de absorver os nutrientes da dieta parecem se desenvolver de forma simultânea. Até o quarto dia de vida, $85 \%$ do amido, $78 \%$ da proteína e $87 \%$ da gordura dietética são digeridos (NOY \& SKLAN, 1995) e, cerca de $90 \%$ da glicose e $80 \%$ da metionina são absorvidas. Uma exceção é a elevada absorção do ácido oléico à eclosão, superior a $85 \%$ sem sofrer grandes alterações com a idade do pintinho (NOY \& SKLAN, 1999).

Nas primeiras horas de vida, os pintos exibem poucas criptas bem definidas e, intensa proliferação de enterócitos na mucosa intestinal (UNI et al., 1998). Segundo Noy \& Sklan (1998, 1999), pintos alimentados imediatamente após a eclosão, tem quase $1 \mathrm{~g}$ de gordura e proteína da

\footnotetext{
1Professor do DAP/CFT/UFPB - Universidade Federal da Paraíba/UFPB - Cidade Universitária - Campus III - 58220-000 - Bananeiras, PB e PPGZ CCA/UFPB - Areia, PB - Bolsista do CNPq-PQ - jvilar@cft.ufpb.br

${ }^{2}$ Aluno do Doutorado Integrado em Zootecnia, PDIZ/CCA/UFPB - Areia, PB - Bolsista Capes - jjordaofilho@yahoo.com.br

${ }^{3}$ Aluno do Doutorado em Zootecnia - Universidade Federal de Lavras/UFLA - Cx. P. 3037 - 37.200-000 - Lavras, MG - Bolsista do CNPq edsonlindolfo@yahoo.com.br

${ }^{4}$ Professor do DAP/CFT/UFPB - Universidade Federal da Paraíba/UFPB - Cidade Universitária - Campus III - 58220-000 - Bananeiras, PB marcelo@cft.ufpb.br
} 
gema do saco vitelínico embrionário desviado para dobrar o volume intestinal, portanto, o jejum neste período deprime a extensão (NOY \& SKLAN, 1999) e atrasa a maturação funcional do intestino (MAIORKA et al., 2003) e, conseqüentemente, afeta o peso corporal (DIBNER, 1997; GEYRA et al., 2001a, b; NOY \& SKLAN, 1999) e, em especial, o peso dos músculos do peito em pintinhos (BIGOT et al., 2003).

O uso de dietas especiais deve afetar a secreção e a atividade enzimática no lúmen e a absorção na mucosa intestinal (NITSAN et al., 1991) e, por isto a qualidade e a quantidade da dieta ingerida são fatores determinantes da taxa de crescimento inicial (DIBNER, 1997). Portanto, o tempo de transição entre dependência dos nutrientes da gema para e o uso dos nutrientes de uma ração sólida torna-se crítico (GEYRA et al., 2001b) e quanto mais rápida essa troca, maior o estímulo ao aproveitamento da gordura e da proteína do resíduo da gema (NOY \& SKLAN, 1999; RUSHBY, 2003).

Com a redução da idade ao abate, nos últimos 40 anos, a permanência dos frangos nos galpões tem sido reduzida em um dia por ano, de modo que, a fase pré-inicial representa cerca de $16 \%$ do tempo compreendido entre a eclosão e o abate das aves (LOTT et al., 1992). Desta forma, cada vez mais, a alimentação na primeira semana ganha importância prática no decorrer do ciclo de vida dos frangos de corte, tendo as constantes alterações nos programas de alimentação, ao longo dos anos, procurado refletir estas mudanças.

A formulação de rações para frangos de corte segue os padrões das recomendações presentes nos manuais das linhagens ou nas tabelas convencionais. Atualmente, não existe uma regra básica quanto aos níveis nutricionais e a duração das fases na literatura. Entretanto, são mais usados os programas de alimentação com duas (NRC, 1994; ROSTAGNO et al., 2000) e com quatro rações (ROSTAGNO et al., 2000, 2005) até 42 dias de idade, mas o efeito desses programas sobre o desempenho de pintos de corte, após um longo período de jejum, tem sido pouco avaliado.

Com a realização do trabalho, objetivou-se avaliar o efeito de programas de alimentação com uma e duas rações sobre o desempenho de frangos de corte, na fase de 1 a 21 dias, submetidos a 72 horas de jejum no período pós-eclosão.

\section{MATERIAL E MÉTODOS}

O experimento foi realizado no Setor de Pesquisas em Nutrição de Aves (SPNA) do Centro de Formação de
Tecnólogos do Campus III da UFPB, localizado no município de Bananeiras - PB. Foram utilizados 576 pintos de corte da linhagem Cobb-Avian Farms com um dia de idade e peso vivo médio de $41,4 \pm 1,1 \mathrm{~g}$. Os pintos foram pesados individualmente, separados por sexo, em seguida, oito machos e oito fêmeas foram distribuídos nos boxes com área de $1,5 \mathrm{~m}^{2}(1,0 \mathrm{~m} \times 1,5 \mathrm{~m})$ e piso coberto com cama de maravalha, em cada parcela experimental. O aquecimento dos pintos foi feito utilizando-se lâmpadas de $100 \mathrm{~W}$, instaladas no centro dos boxes.

As aves não tiveram acesso à ração e a água durante as primeiras 72 horas pós-eclosão, cronometradas a partir do saque dos pintos no nascedouro. Decorrido este período, as rações e a água foram distribuídas à vontade e, adotou-se o programa de luz contínuo (24 h de luz natural+artificial). O experimento foi constituído de três tratamentos com doze repetições de 16 aves cada, arranjados em delineamento inteiramente casualizado. Foram utilizados os seguintes programas de alimentação (PA) apresentados na Tabela 1: PA = ração inicial com $21,4 \% \mathrm{~PB}$ e $3.000 \mathrm{kcal} / \mathrm{kg}$ EM da ração (ROSTAGNO et al., 2000); $\mathrm{PA}_{2}=$ ração pré-inicial com $21,92 \%$ PB e $2.950 \mathrm{kcal} /$ $\mathrm{kg} \mathrm{EM}+$ ração inicial com 20,9\% PB e $3.000 \mathrm{kcal} / \mathrm{kg}$ EM (ROSTAGNO et al., 2005); e, $\mathrm{PA}_{3}=$ ração pré-inicial com $23,0 \% \mathrm{~PB}$ e $2.930 \mathrm{kcal} / \mathrm{kg}$ EM + ração inicial com 21,0\% PB e $3.050 \mathrm{kcal} / \mathrm{kg}$ EM da ração. O PA 3 era utilizado por uma integração avícola local.

As variáveis consumo de ração (g/ave), ganho de peso (g/ave) e conversão alimentar $(\mathrm{kg} / \mathrm{kg})$ foram avaliadas nos períodos de 1 a 7 e 1 a 21 dias de idade.

As médias das variáveis foram submetidas à análise de variância pelo teste $\mathrm{F}(\mathrm{P} \leq 0,05)$, e para as comparações das médias utilizou-se o teste de Student Newman-Keuls SNK $(\mathrm{P} \leq 0,05)$, através do "software" SAEG, desenvolvido pelo Centro de Processamento de Dados - CPD da Universidade Federal de Viçosa (UFV, 1993).

\section{RESULTADOS E DISCUSSÃO}

Os valores de temperatura e umidade no galpão experimental foram registrados diariamente às 8 e 16 horas por aparelho termohigrometro e as médias máximas e mínimas de temperatura foram, respectivamente, de 22,3 e $30,7^{\circ} \mathrm{C}$, e de umidade foram de 60,5 e $91,9 \%$.

Os resultados de consumo de ração, ganho de peso e conversão alimentar dos pintos de corte submetidos a jejum de 72 horas pós-eclosão, avaliado na primeira semana de vida (1 a 7 dias) e de 1 a 21 dias de idade recebendo os programas com dietas pré-iniciais e iniciais, são apresentados na Tabela 2 . 
TABELA 1 - Composição alimentar e calculada das rações dos três programas básicos de alimentação (PA).

\begin{tabular}{|c|c|c|c|c|c|}
\hline \multirow[b]{2}{*}{ Ingredientes } & \multirow{2}{*}{$\frac{\mathbf{P A}_{1}{ }^{1}}{1 \text { a } 21}$} & \multicolumn{2}{|c|}{$\mathbf{P A}{ }_{2}^{l}$} & \multicolumn{2}{|c|}{$\mathbf{P A}_{3}{ }^{2}$} \\
\hline & & 1 a 7 & 8 a 21 & 1 a 7 & 8 a 21 \\
\hline Milho (8,3\% PB) & 59,44 & 58,75 & 61,33 & 55,41 & 59,28 \\
\hline Farelo de soja (46\% PB) & 35,14 & 36,34 & 33,60 & 39,47 & 34,25 \\
\hline Calcário calcítico & 0,99 & 1,00 & 0,97 & 0,90 & 1,06 \\
\hline Fosfato bicálcico & 1,82 & 1,90 & 1,77 & 2,06 & 1,88 \\
\hline DL - Metionina (99\%) & 0,23 & 0,25 & 0,23 & 0,30 & 0,30 \\
\hline L - Lisina $\bullet \mathrm{HCl}(78,4 \%)$ & 0,18 & 0,19 & 0,19 & 0,11 & 0,15 \\
\hline Óleo vegetal & 1,52 & 0,88 & 1,22 & 1,05 & 2,39 \\
\hline Cloreto de colina (70\%) & 0,06 & 0,06 & 0,06 & 0,06 & 0,06 \\
\hline Suplemento vitamínico ${ }^{3}$ & 0,05 & 0,05 & 0,05 & 0,05 & 0,05 \\
\hline Suplemento mineral $^{4}$ & 0,05 & 0,05 & 0,05 & 0,05 & 0,05 \\
\hline Sal comum & 0,45 & 0,46 & 0,44 & 0,46 & 0,44 \\
\hline Anticoccidiano $^{5}$ & 0,05 & 0,05 & 0,05 & 0,05 & 0,05 \\
\hline Promotor de crescimento ${ }^{6}$ & 0,02 & 0,02 & 0,02 & 0,02 & 0,02 \\
\hline Antioxidante $^{7}$ & 0,01 & 0,01 & 0,01 & 0,02 & 0,02 \\
\hline Total & 100,00 & 100,00 & 100,00 & 100,00 & 100,00 \\
\hline \multicolumn{6}{|l|}{ Composição química } \\
\hline $\mathrm{PB}(\%)$ & 21,40 & 21,92 & 20,88 & 23,00 & 21,00 \\
\hline EMAn, kcal/kg & 3.000 & 2.950 & 3.000 & 2.930 & 3.050 \\
\hline $\mathrm{Ca}(\%)$ & 0,96 & 0,99 & 0,94 & 1,00 & 1,00 \\
\hline $\operatorname{Pd}(\%)$ & 0,45 & 0,47 & 0,44 & 0,50 & 0,46 \\
\hline Met (\%) & 0,56 & 0,58 & 0,55 & 0,64 & 0,62 \\
\hline Met+Cis (\%) & 0,90 & 0,93 & 0,88 & 1,00 & 0,95 \\
\hline Lis $(\%)$ & 1,26 & 1,31 & 1,24 & 1,32 & 1,22 \\
\hline $\mathrm{EE}(\%)$ & 4,04 & 3,40 & 3,79 & 3,51 & 4,89 \\
\hline $\mathrm{Na}(\%)$ & 0,22 & 0,22 & 0,22 & 0,22 & 0,22 \\
\hline
\end{tabular}

${ }^{1}$ Segundo Rostagno et al. (2000, 2005).

${ }^{2}$ Empresa nordestina de integração de aves.

${ }^{3}$ Enriquecimento por kg de ração: Vitamina A 5000 U.I, Vitamina D3 1250 U.I, Vitamina E 3 U.I, Vitamina K 0,8 mg, Vitamina $\mathrm{B}_{12}$ 5,5, Niacina 12,5 mg, Ácido Fólico 0,2 mg, Ácido Pantotênico $5 \mathrm{mg}$, Selênio 0,15 mg, Antioxidante 20g.

${ }^{4}$ Enriquecimento por kg de ração: Manganêz $75 \mathrm{mg}$, Zinco $5 \mathrm{mg}$, Ferro $5 \mathrm{mg}$, Cobre $8 \mathrm{mg}$, Iodo 0,75 mg.

${ }^{5}$ Coban.

${ }^{6}$ Bacitracina de zinco.

${ }^{7}$ Butil Hidroxi Tolueno - BHT.

Ciênc. agrotec., Lavras, v. 31, n. 1, p. 206-211, jan./fev., 2007 
TABELA 2 - Desempenho de pintos de corte, após jejum de 72 horas pós-eclosão, avaliado na primeira semana de vida e de 1 a 21 dias de idade, em função do programa de alimentação.

\begin{tabular}{lccc}
\hline $\begin{array}{c}\text { Programa } \\
\text { alimentar }\end{array}$ & $\begin{array}{c}\text { Consumo de ração } \\
\text { (g/ave) }\end{array}$ & $\begin{array}{c}\text { Ganho de peso } \\
\text { (g/ave) }\end{array}$ & $\begin{array}{c}\text { Conversão alimentar } \\
\text { (kg/kg) }\end{array}$ \\
\hline & & 1 a 7 dias & \\
\hline $\mathrm{PA}_{1}$ & 144,50 & $80,05^{\mathrm{b}}$ & $1,805^{\mathrm{a}}$ \\
$\mathrm{PA}_{2}$ & 143,77 & $92,98^{\mathrm{a}}$ & $1,546^{\mathrm{b}}$ \\
$\mathrm{PA}_{3}$ & 146,68 & $95,64^{\mathrm{a}}$ & $1,534^{\mathrm{b}}$ \\
\hline $\mathrm{CV}(\%)$ & 3,046 & 9,308 & 10,505 \\
\hline & & 1 a 21 dias & \\
\hline $\mathrm{PA}_{1}$ & $1169^{\mathrm{b}}$ & $671,57^{\mathrm{b}}$ & 1,741 \\
$\mathrm{PA}_{2}$ & $1351^{\mathrm{a}}$ & $779,77^{\mathrm{a}}$ & 1,732 \\
$\mathrm{PA}_{3}$ & $1341^{\mathrm{a}}$ & $779,76^{\mathrm{a}}$ & 1,720 \\
\hline $\mathrm{CV}(\%)$ & 10,388 & 8,067 & 9,367 \\
\hline
\end{tabular}

${ }^{a, b}$ Médias nas colunas, seguidas de letras iguais, não diferem pelo teste SNK (Pe’0,05).

${ }^{1}$ Para maiores esclarecimentos sobre os programas de alimentação retornar a Tabela 1 do tópico Material e Métodos.

No período de 1 a 7 dias os diferentes programas alimentares afetaram $(\mathrm{P} \leq 0,05)$ o ganho de peso e a conversão alimentar, enquanto que no período de 1 a 21 dias, os programas com dietas pré-iniciais proporcionaram maior consumo e melhor ganho de peso dos pintos $(\mathrm{P} \leq 0,05)$.

É provável que a restrição alimentar pós-eclosão retardou o desenvolvimento da mucosa intestinal, em especial, as funções digestivas e absortivas e a maior densidade dos nutrientes, especialmente, metionina + cistina e lisina nos programas de alimentação $\mathrm{P}_{2}$ e $\mathrm{P}_{3}$, é a provável explicação para o melhor desempenho das aves recebendo as dietas pré-iniciais. Segundo Uni et al. (1998), a restrição alimentar de 36 horas de duração estimula a formação de aglomerados de microvilos na superfície apical do jejuno de pintos e reduz a área de absorção. Portanto, a oferta de dietas com alta concentração de nutrientes digestíveis para pintos que foram submetidos à restrição alimentar deve favorecer o desempenho das aves durante a fase pré-inicial.

Noy \& Sklan (2002) também mostraram que as absorções de glicose e de metionina em pintos de corte são afetadas pela restrição alimentar de 96 horas de duração pós-eclosão. Assim, a redução da área de absorção em função da falta de alimento, no tratogastrintestinal, pode limitar a capacidade de absorção dos nutrientes. Estes estudos descreveram de modo geral, que a resposta adaptativa do intestino e as funções de absorção e digestão dependem do tempo de jejum a qual os animais são submetidos. Portanto, quanto mais cedo o pintinho for alimentado maiores serão as sínteses e secreção enzimática do pâncreas, estimulando o aproveitamento dos nutrientes da ração (SKLAN \& NOY, 2000). A maior atividade de síntese de enzimas no pâncreas está associada ao estímulo da presença do substrato e da elevada expressão gênica do mRNA na codificação de algumas enzimas digestivas (SKLAN et al., 2003).

O melhor desempenho dos pintos com o aumento da concentração de proteína na ração de 21, para 22, e $23 \%$ e, conseqüentemente, de lisina e metionina+cistina, do programa convencional para os programas com dietas pré-iniciais, sugere que os processos intestinais em pintos de corte, submetidos a longos períodos de restrição alimentar são sensíveis à qualidade da dieta presente no lúmen intestinal. Segundo Tarachai \& Yamauchi (2000), o desenvolvimento das vilosidades intestinais é substrato dependente, sendo estimulado pelos nutrientes disponíveis para o processo de absorção entérica. Sklan \& Noy (2003b) observaram que as enzimas digestivas aumentam com o avanço da idade dos pintos, com o aumento da atividade da tripsina mais rapidamente que da lipase e que a maior atividade da tripsina, traduz-se em elevado ganho de peso. Em um outro estudo, avaliando a necessidade de proteína bruta e aminoácidos essenciais para pintos de uma semana de idade, Sklan \& Noy (2003a) observaram que o aumento da proteína e dos aminoácidos eleva o ganho de peso das aves. 
Como ocorre redução no teor de proteína e de gordura do resíduo da gema presente no intestino do pintinho durante a fase de restrição alimentar, esta redução parece ser ainda maior com a oferta de ração nas primeiras horas pós-eclosão (NOY \& SKLAN, 1999), indicando que a presença de alimento exógeno no lúmen intestinal estimula a eficiência do processo digestivo de pintinhos recémeclodidos.

Os resultados de desempenho dos frangos de 1 a 21 dias de idade do $\mathrm{PA}_{2}$ e do $\mathrm{PA}_{3}$ foram semelhantes $(\mathrm{P}>0,05)$, mostraram que esses programas influenciaram 0 desempenho das aves de forma semelhante.

$\mathrm{O}$ peso vivo das aves alimentadas com as rações pré-iniciais, também foi superior aos daquelas alimentadas com a dieta do programa convencional $(\mathrm{P} \leq 0,05)$ nos períodos de 1 a 7 e de 1 a 21 dias de idade (Figura 1).

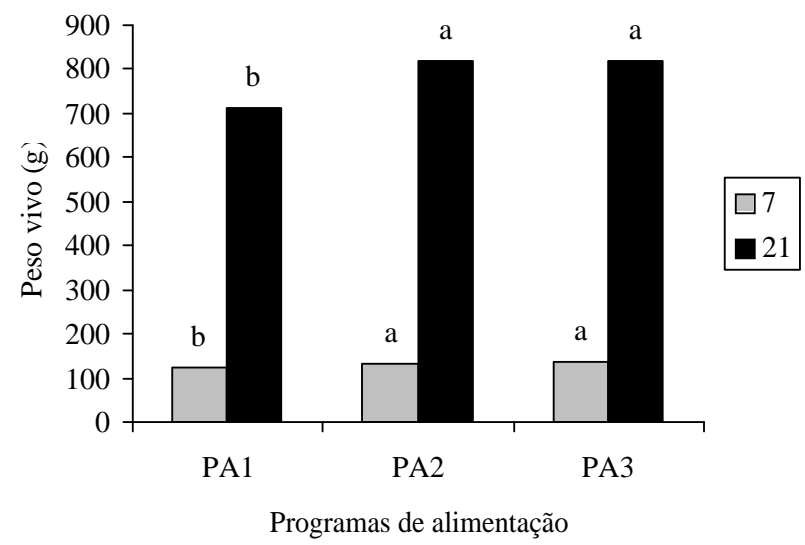

FIGURA 1 - Peso vivo de pintos de corte aos 7 e 21 dias em função dos programas de alimentação com ração inicial $\left(\mathrm{PA}_{1}\right)$ e com rações pré-iniciais $\left(\mathrm{PA}_{2}\right)$ e $\left(\mathrm{PA}_{3}\right)$.

Aos sete dias, o peso vivo dos pintos que receberam as dietas pré-iniciais foi maior que o apresentado por aqueles do programa convencional, influenciando maiores ganhos de peso diário de 13,28 g do $\mathrm{PA}_{2}$ e de 13,66 $\mathrm{g}$ do $\mathrm{PA}_{3}$ em comparação com $11,4 \mathrm{~g}$ dos pintos do $\mathrm{PA}_{1}$. Assim, o uso de programas de alimentação com ração préinicial sugere melhor atendimento das necessidades nutricionais em pintos de corte submetidos a longos períodos de jejum pós-eclosão. Este resultado corrobora a afirmação de Sklan (2003) sobre a influência positiva das dietas pré-iniciais no desempenho de pintos de corte na primeira semana de vida.

Considerando o peso das aves do programa convencional como $100 \%$, verificou-se que aos 7 e aos 21 dias, o peso das aves do $\mathrm{PA}_{2}$ foi, respectivamente, $10 \mathrm{e}$
$15 \%$ e do $\mathrm{PA}_{3}$ foi 12 e $15 \%$, superiores aos pesos das aves do programa convencional. Este resultado corrobora a afirmação de Nitsan et al. (1991), que o uso de dietas préiniciais e iniciais atende melhor a alta demanda nutricional dos pintinhos nos primeiros dias pós-eclosão porque eleva a secreção e a atividade de enzimas digestivas no lúmen intestinal, beneficiando a digestão e a absorção dos nutrientes da ração.

Os resultados do presente trabalho indicam a adoção de dietas pré-iniciais e iniciais em programas de alimentação de pintos de corte submetidos a uma condição prática de 72 horas de jejum pós-eclosão, em comparação com programas que utilizam apenas dieta inicial, sendo este último desaconselhável para as linhagens modernas de frangos de corte que concentram, segundo Lott et al. (1992) cerca de $16 \%$ do crescimento na primeira semana de vida.

A semelhança de ganho de peso entre os pintos recebendo o programa 2 e o 3 , e a maior concentração de nutrientes nas rações deste último programa, indica que os níveis nutricionais recomendados nas Tabelas Brasileiras versão 2005, para as fases pré-inicial e inicial otimizam o desempenho de pintos de corte até 21 dias de idade.

\section{CONCLUSÃO}

Recomendam-se programas de alimentação com dietas pré-inicial e inicial para pintos submetidos a períodos de 72 horas de atraso na alimentação pós-eclosão.

\section{AGRADECIMENTOS}

Os autores agradecem à Granja Planalto, especialmente ao Dr. Flávio Mohallen das Neves, pelo apoio recebido com a doação das aves.

\section{REFERÊNCIAS BIBLIOGRÁFICAS}

BIGOT, K.; TAOUIS, M.; PICARD, M.; TESSERAUD, S. Early post-hatching starvation delays p70 S6 kinase activation in the muscle of neonatal chicks. British Journal of Nutrition, Cambridge, v. 90, n. 6, p. 1023-1029, 2003.

DIBNER, J. J. Early development of the digestive tract and the nutritional implications. Poultry Digest, [S.l.], p. 16-19, 1997.

GEYRA, A.; UNI, Z.; GAL-GARBER, O.; GUY, D.; SKLAN, D. Starving affects CDX gene expression during small intestinal development in the chick. British Journal of Nutrition, Cambridge, v. 85, p. 911-917, 2002. 
GEYRA, A.; UNI, Z.; SKLAN, D. Enterocyte dynamics and mucosal development in the posthatch chick. Poultry Science, Champaign, v. 80, p. 776-782, 2001a.

GEYRA, A.; UNI, Z.; SKLAN, D. The effect of fasting at different ages on growth and tissue dynamics in the small intestine of the young chick. British Journal of Nutrition, Cambridge, v. 86, n. 1, p. 53-61, 2001b.

LOTT, B. D.; DAY, E. J.; DEATON, J. W. The effect of temparature, dietary energy level, and corn particle size on broiler performance. Poultry Science, Champaign, v. 71, p. 618-624, 1992.

MAIORKA, A.; SANTIN, E.; DAHLKE, F.; BOLELI, I. C.; FURLAN, R. L.; MACARI, M. Posthatching water and feed deprivation affect the gastrointestinal tract and intestinal mucosa development of broiler chicks. Journal Applied Poultry Research, Champaign, v. 12, n. 4, p. 483492, 2003.

NATIONAL RESEARCH COUNCIL. Nutrient requeriments of poultry. 9 . ed. Washington, DC: National Academy, 1994. 155 p.

NITSAN, Z.; BEM-AVRAHAM, G.; ZOREF, Z.; NIR, I. Growth and development of the digestive organs and some enzymes in broiler chicks after hatching. British Poultry Science, London, v. 32, p. 515-523, 1991.

NOY, Y.; SKLAN, D. Digestion and absorption in the young chick. Poultry Science, Champaign, v. 74, p. 366-373, 1995.

NOY, Y.; SKLAN, D. Energy utilization in newly hatched chicks. Poultry Science, Champaign, v. 78, p. 1750-1756, 1999.

NOY, Y.; SKLAN, D. Metabolic responses to early nutrition. Journal Applied Poultry Research, Athens, v. 77, p. 437 451, 1998.

NOY, Y.; SKLAN, D. Nutrient use in chicks during the first week posthatch. Poultry Science, Champaign, v. 81, p. 391-399, 2002.

ROSTAGNO, H. S.; ALBINO, L. F. T.; DONZELE, J. L.; GOMES, P. S.; OLIVEIRA, R. F. de; LOPES, D. C.; PEREIRA,
A. S.; BARRETO, S. L. T. de. Tabelas brasileiras para suínos e aves: composição de alimentos e exigências nutricionais. Viçosa: UFV, 2000. 141 p.

ROSTAGNO, H. S.; ALBINO, L. F. T.; DONZELE, J. L.; GOMES, P. S.; OLIVEIRA, R. F. de; LOPES, D. C.; PEREIRA, A. S.; BARRETO, S. L. T. de. Tabelas brasileiras para aves e suínos: composição de alimentos e exigências nutricionais. 2. ed. Viçosa: UFV, 2005. 186 p.

RUSHBY, A. First week of life. Poultry Word, [S.1.], n. 6, p. 7, 2003.

SKLAN, D. Fat and carbohydrate use in posthatch chicks. Poultry Science, Champaign, v. 82, p. 117-122, 2003.

SKLAN, D.; GEYRA, A.; TAKO, E.; GAL-GERBER, O.; UNI, Z. Ontogeny of brush border carbohydrate digestion and uptake in the chick. British Journal of Nutrition, Cambridge, v. 89, p. 747-753, 2003.

SKLAN, D.; NOY, Y. Crude protein and essential amino acid requirements in chicks during the first week posthatch. British Poultry Science, Cambridge, v. 44, n. 2, p. 266-274, 2003a.

SKLAN, D.; NOY, Y. Functional development and intestinal absorption in the young poult. British Poultry Science, Cambridge, v. 44, n. 4, p. 651-658, 2003b.

SKLAN, D.; NOY, Y. Hydrolysis and absorption in the small intestines of posthatch chicks. Poultry Science, Washington, v. 79, p. 1306-1310, 2000.

TARACHAI, P.; YAMAUCHI, K. Effects of luminal nutrient absorption, intraluminal physical stimulation, and intravenous parenteral alimentation on the recovery responses of duodenal villus morphology following feed withdrawal in chickns. Poultry Science, Champaign, v. 79, p. 1578-1585, 2000.

UNI, Z.; GANOT, S.; SKLAN, D. Posthatch development of mucosal function in the broiler small intestine. Poultry Science, Champaign, v. 77, p. 75-82, 1998.

UNIVERSIDADE FEDERAL DE VIÇOSA. Central de processamento de dados. SAEG - Sistema para análise estatística e genética. Versão 5.0. Viçosa, 1993. 